\title{
BIOCHEMICAL AND CYTOCHEMICAL STUDY OF TRIMETAPHOSPHATASE ACTIVITY IN MAMMALIAN TISSUES ${ }^{1,2,3}$
}

\author{
Harumichi SEgUChi, Toshihiro KOBAYASHI, Teruhiko OKADA, \\ Shu-XIN ZHANG, Shoji NISHIYAMA* and Eva GARCIA DEL SAZ \\ Department of Anatomy and Cell Biology, and Department of Otolaringology", \\ Kochi Medical School, Kohasu, Okoh-cho, Nankoku, Kochi 783
}

Received for publication October 7, 1991 and in revised form November 14, 1991

\begin{abstract}
Trimetaphosphatase (TMPase) was biochemically and cytochemically investigated using rat and guinea pig tissues. TMPase was partially purified, and its activity was visualized and measured by the method of Doty et al. (J. Histochem. Cytochem. 25 : 1381, 1977), using a dot-blot apparatus. TMPase was salted out in fractions of 60-80\% ammonium sulfate. TMPase activity was observed in early protein fractions of Sephadex G-100 column. The molecular weight and pI of the partially purified TMPase were 130KD and 6.1, respectively. Electrophoretically, TMPase and acid phosphatase (ACPase) activities were observed in different bands. The present results clearly demonstrated that TMPase and ACPase are two different proteins. Cytochemically, the TMPase activity was elucidated using an improved method which employs cerium salt as capture agert, and the results were compared with those of the lead-based method. The incubation medium of the cerium-based method contained $20 \mathrm{~mm}$ acetate buffer, pH 3.9, 2 mM cerium chloride, $1 \mathrm{~mm}$ trimetaphosphate, $5 \%$ sucrose, and $0.00015 \%$ Triton $\mathrm{X}-100$. The localization of the TMPase activity differed from that of ACPase in all tissues employed. TMPase activity was observed mainly in tubular structures. Using the cerium-based method, nonspecific precipitates were considerably reduced as compared with the lead-based method.
\end{abstract}

In addition to ACPase, which is commonly demonstrated cytochemically after incubation in a medium containing $\beta$-glycerophosphate as substrate, adjusted to $\mathrm{pH} 5.0(13,21)$, TMPase activity, which can be detected after incubation in a medium containing TMP as substrate, adjusted at the optimal $\mathrm{pH}$ of 3.9 , has recently been employed in several tissues, and is considered to be a reliable marker enzyme of the lysosomal system $(1,12,14-16)$. TMPase has been reported to be present in basal tubular structures of the

Correspondence and reprint requests : Dr. H. Seguchi, Department of Anatomy and Cell Biology, Kochi Medical School, Kohasu, Okoh-cho, Nankoku, Kochi 783, Japan. Tel. No.: (0888) 66-5811 Fax No.: (0888) 66-7374

1 Dedicated to Professor Kazuo Ogawa in memory of his retirement.

2 Part of this work has been presented at the 30th Annual Meeting of the Japanese Society of Histochemistry and Cytochemistry held in Kyoto on October 23-25, 1989.

3 Part of this work was supported by Grants-in-Aid for Scientific Research (B) No.61480092 and No.01480408 from the Ministry of Education, Science and Culture of Japan. pancreatic acinar cells. These tubular structures are considered to be related with pinocytosis since they were found to contain intravenously administered tracers like HRP and cationized ferritin $(12,15)$.

Until now, the lead-based method has been the method of choice for the cytochemical detection of TMPase (18, 22). Recently, however, methods employing cerium as capture agent are gaining wider acceptance because they produce much less nonspecific precipitate than the lead-based method $(10,19,20)$. The biochemical properties of TMPase were first investigated by Kornberg (11) and by Berg and Gordon (2), but our knowledge of this enzyme is still poor. In this paper we report the partial purification, and the application of the cerium-based method for the cytochemical detection of the enzyme activity.

\section{MATERIALS AND METHODS}

Cytochemical Procedure

Hartley guinea pigs weighing $250-300 \mathrm{~g}$ were us- 
ed. The spiral ligament was extirpated from the animals after decapitation, and fixed in $2 \%$ glutaraldehyde in $0.1 \mathrm{M}$ cacodylate buffer, $\mathrm{pH} 7.4$, containing $5 \%$ sucrose for $1 \mathrm{hr}$ at $0-4^{\circ} \mathrm{C}(23)$. As control, pancreata extirpated from rats were fixed in the same fixative under the same conditions. In addition to the lead method of Doty et al. (5), the cerium-based method was used for the detection of TMPase activity. The incubation medium consisted of $20 \mathrm{~mm}$ acetate buffer, $\mathrm{pH} 3.9,2 \mathrm{~mm}$ cerium chloride, $1 \mathrm{~mm}$ sodium trimetaphosphate, $5 \%$ sucrose, and $0.00015 \%$ Triton X-100. For the detection of ACPase, the method of Robinson and Karnovsky (20) was used. The two enzymes were incubated in their respective media for $60 \mathrm{~min}$ at $37^{\circ} \mathrm{C}$. After incubation the materials were rinsed in $20 \mathrm{~mm}$ acetate buffer and then washed in $0.1 \mathrm{M}$ cacodylate buffer. The tissues were postfixed in $1 \% \mathrm{OsO}_{4}$ for $1 \mathrm{hr}$, at room temperature, dehydrated in a graded series of ethanols and embedded in Spurr's epoxy resin (24). Semithin sections of $0.2-0.5 \mu \mathrm{m}$ in thickness were cut on an Ultracut $\mathrm{E}$ (Richert-Jung AG, Vienna, Austria) and observed under a JEM-100S (JEOL Co., Ltd., Tokyo, Japan).

Tracer experiments were also performed with guinea pigs by injecting $100 \mu \mathrm{l}$ of $5 \% \mathrm{HRP}$ into the subarachnoidal space through the occipital region. One hour after administration of HRP, the spiral ligament was extirpated and processed according to the method of Graham and Karnovsky (7).

Biochemical Procedure

Hartley guinea pigs weighing 400-500 g, and Wistar rats weighing 200-300 g were used. Twenty grams of kidney cortex, extirpated after decapitation, from each animal species was minced using a metal sieve while adding $100 \mathrm{ml}$ of $0.25 \mathrm{M}$ sucrose- $0.2 \mathrm{M}$ $\mathrm{KCl}$ solution dropwise, and homogenized in teflonglass. The homogenate was centrifuged at $2000 \times \mathrm{g}$ for $10 \mathrm{~min}$ and the supernatant was collected and centrifuged again at $6000 \times \mathrm{g}$ for $10 \mathrm{~min}$. The supernatant was discarded and the precipitate was resuspended in $20 \mathrm{ml}$ of $0.7 \mathrm{M}$ sucrose- $0.2 \mathrm{M} \mathrm{KCl}$ solution and centrifuged at $2000 \times \mathrm{g}$ for $10 \mathrm{~min}$. The supernatant was centrifuged at $10,000 \times \mathrm{g}$ for $30 \mathrm{~min}$ and the precipitate, the lysosomal fraction, was resuspended in $50 \mathrm{~mm}$ acetate buffer, $\mathrm{pH} 3.9$, containing $5 \mathrm{ml}$ of $5 \mathrm{~mm}$ mercaptoethanol. This fraction was frozen and thawn 4 times and centrifuged at $100,000 \times \mathrm{g}$ for $30 \mathrm{~min}$. The supernatant was used for the biochemical assay. For the protein salting out, ammonium sulfate was employed. The gel filtration was performed through a Sephadex G-100 column and the protein was eluted out with $50 \mathrm{~mm}$ acetate buffer, $\mathrm{pH} 3.9$, containing $5 \mathrm{~mm}$ mercaptoethanol. Five milliliters of protein solution per tube was discharged at a velocity of $20 \mathrm{ml} / \mathrm{hr}$. For ion exchange chromatography, $4 \mathrm{ml}$ of protein solution per tube was eluted out through a DEAE-cellulose column balanced with $50 \mathrm{~mm}$ Tris$\mathrm{HCl}$ buffer, $\mathrm{pH} 8.0$, at a flow rate of $10 \mathrm{ml} / \mathrm{hr}$.

Detection of TMPase activity

The wells of the dot-blot apparatus (Bio-Rad Laboratories, Richmond, CA, USA) were filled with $0.2 \mathrm{ml}$ of protein solution from each tube. The protein was adsorbed onto the nitrocellulose sheet $(4,9)$. The TMPase activity of the dots on the nitrocellulose membrane was histochemically visualized with $0.5 \%$ ammonium sulfide after incubation in the medium of Doty et al. (5), at $37^{\circ} \mathrm{C}$ for $30 \mathrm{~min}$. Samples of $10 \mu \mathrm{l}$ of protein solution were subjected to polyacrylamide gel electrophoresis in 5\% acrylamide gels at $45 \mathrm{~mA}$ for 2 hr in an LKB 2177 Multiphor (LKB Produkter AB, Bromma, Sweden). The ACPase and TMPase activities on the gel plate were detected by the methods of Gomori (8) and of Doty et al. (5), respectively. Isoelectric focusing was performed using an LKB Ampholine (LKB Produkter AB, Bromma, Sweden), and the ac-

FIG. 1. Electron micrograph of a normal fibroblast in the spiral ligament of the guinea pig inner ear. Round and tubular lysosome-like structures are observed in the cytoplasm. $\times 23,000 \quad \mathrm{Bar}=1 \mu \mathrm{m}$.

Fig. 2. The localization of TMPase activity in the fibroblasts in the spiral ligament of the guinea pig inner ear incubated in the lead-based medium. The enzyme activity was detected in the abundant round and tubular structures in the cytoplasm. $\times 6,000 \quad$ Bar $=1 \mu \mathrm{m}$.

Fig. 3. The TMPase activity was observed in the round and tubular structures in the fibroblasts of the spiral ligament of the guinea pig inner ear incubated in the cerium-based medium. $\times 5,600 \quad \mathrm{Bar}=1 \mu \mathrm{m}$.

Fig. 4. Localization of ACPase activity in the fibroblasts of the guinea pig spiral ligament incubated in the cerium-based medium. The enzyme activity was localized in the Golgi complex and in the round and tubular structures. $\times 10,000$ $\mathrm{Bar}=1 \mu \mathrm{m}$.

Fig. 5. HRP uptake experiment in the fibroblasts of the spiral ligament of the guinea pig inner ear. The DAB-positive reaction product was detected in the round and tubular structures, which coincide with the localization of TMPase activity. $\times 23,000$ $\mathrm{Bar}=1 \mu \mathrm{m}$.

Fig. 6. Localization of TMPase activity in the rat pancreatic exocrine acinar cells by the cerium-based method. The enzyme activity was detected in the tubular structures in the basal cytoplasm. $\times 8,500 \quad \mathrm{Bar}=1 \mu \mathrm{m}$. 


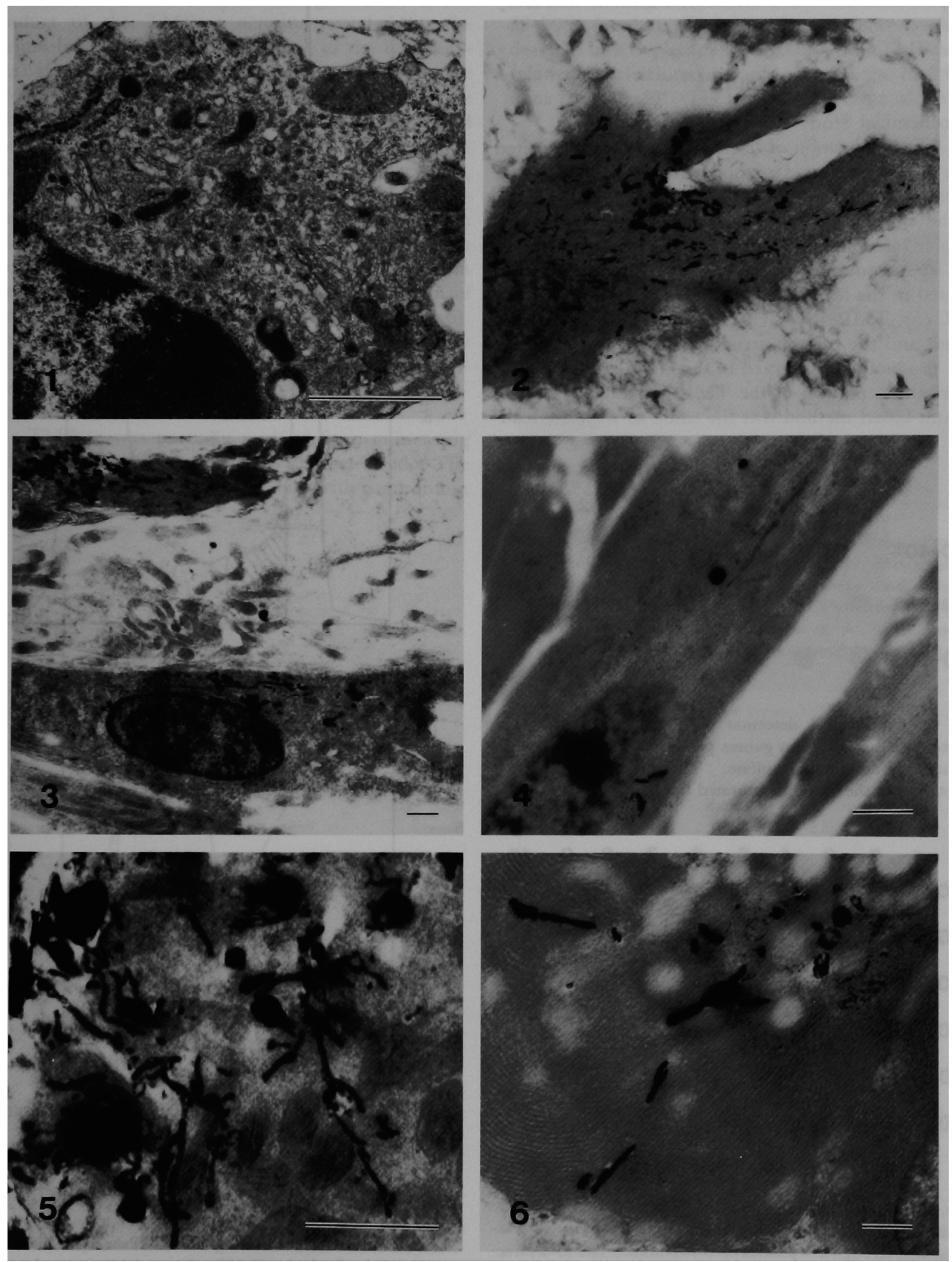


tivity of TMPase was detected by the method of Doty et al.

\section{RESULTS}

\section{Cytochemical Study}

The localization of the TMPase activity detected with the cerium-based method was compared with that revealed by the lead-based method. In the fibroblasts of the spiral ligament of the guinea pig inner ear, tubular lysosome-like structures were found in addition to the round lysosomes (Fig. 1). In the specimens reacted in the lead-based incubation medium of Doty et al. (5), TMPase activity was localized in both the round and the tubular structures (Fig. 2). No reaction product was observed in the Golgi complex. The distribution pattern of the TMPase activity with the cerium-based method was the same as with the lead-

\section{$\begin{array}{lllllll}1 & \frac{1}{2} & \frac{1}{4} & \frac{1}{8} & \frac{1}{16} & \frac{1}{32} & \frac{1}{64}\end{array}$}

\section{$0-40 \%$}

\section{0-60\%}

\section{$60-80 \%$}

Fig. 7. Biochemical detection of TMPase activity. The lysosomal protein from guinea pig kidney cortex was salted out with ammonium sulfate. The enzyme activity was detected in the $60-80 \%$ saturated fractions.

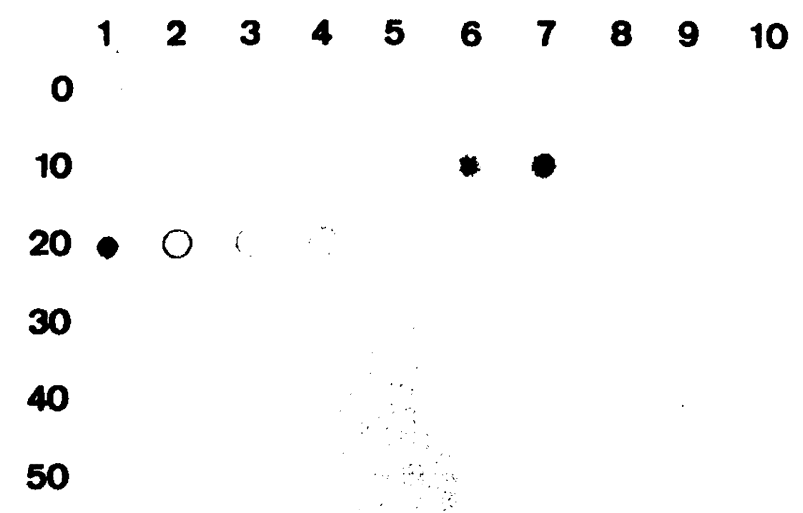

Fic. 8. Biochemical detection of TMPase activity. The lysosomal protein from guinea pig kidney cortex was fractionated through a Sephadex G-100 column. The 15-24 fractions revealed enzyme activity.

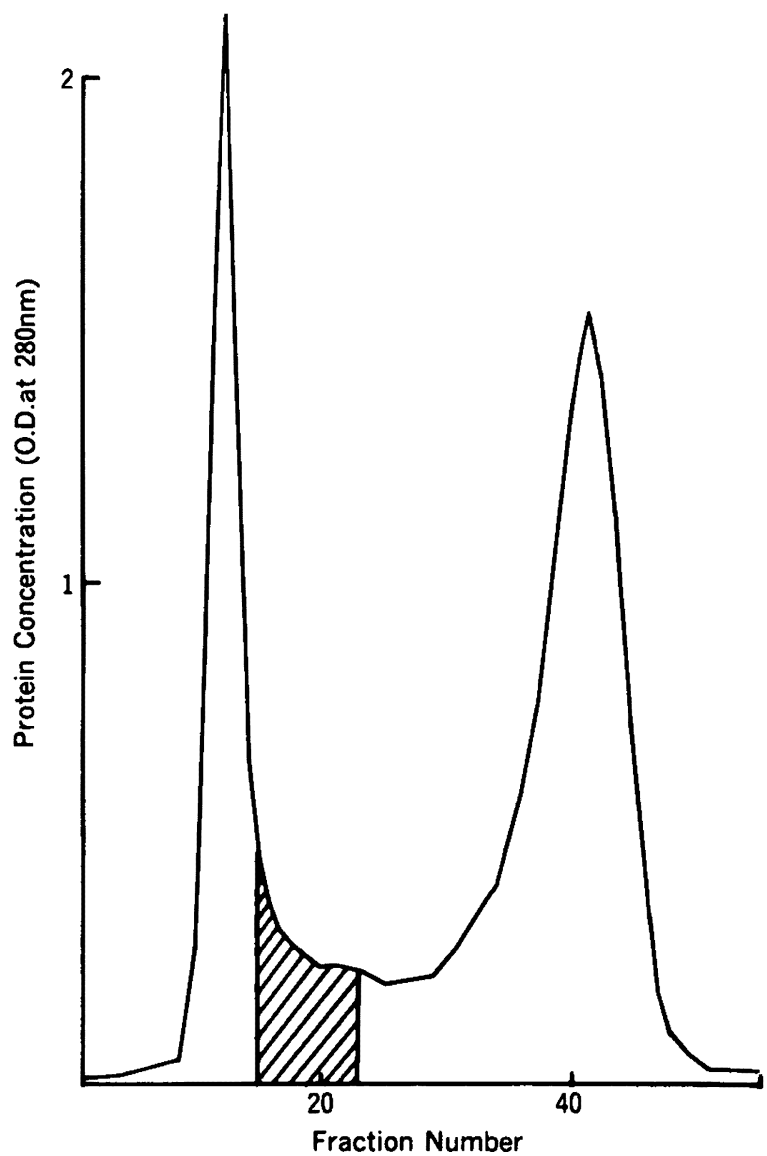

Fig. 9. Extraction of the lysosomal protein by Sephadex G100 column chromatography. TMPase activity was detected in relatively early fractions.

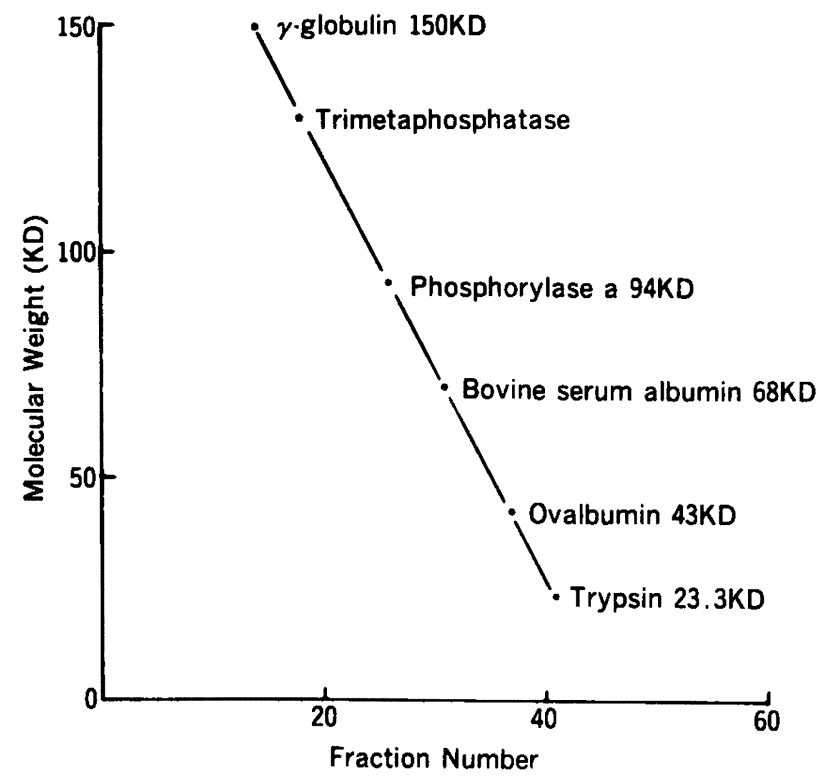

Fig. 10. The molecular weight of TMPase was estimated as $130 \mathrm{KD}$ by Sephadex G-100 column chromatography. 
based method. However, the fine granular reaction product of the TMPase activity revealed by the cerium-based method was confined to the lysosomelike structures and nonspecific precipitates were seldom encountered (Fig. 3). ACPase activity, on the other hand, was only found in some scattered round and tubular lysosomes and in the Golgi complex (Fig. 4). In the specimens of the HRP tracer experiment, $\mathrm{DAB}$ reaction was found in round and tubular structures. The distribution pattern of the DAB reaction coincided with that of TMPase activity (Fig. 5). In the control specimens, TMPase activity was found in the long tubular structures in the basal cytoplasm of the exocrine acinar cells of rat pancreas (Fig. 6). These results were consistent with those reported by Oliver and her colleagues $(12,14-16)$ using the leadbased method.

Biochemical Study

TMPase was partially purified from guinea pig kidney cortex, and biochemically characterized. The lysosomal proteins were salted out with ammonium

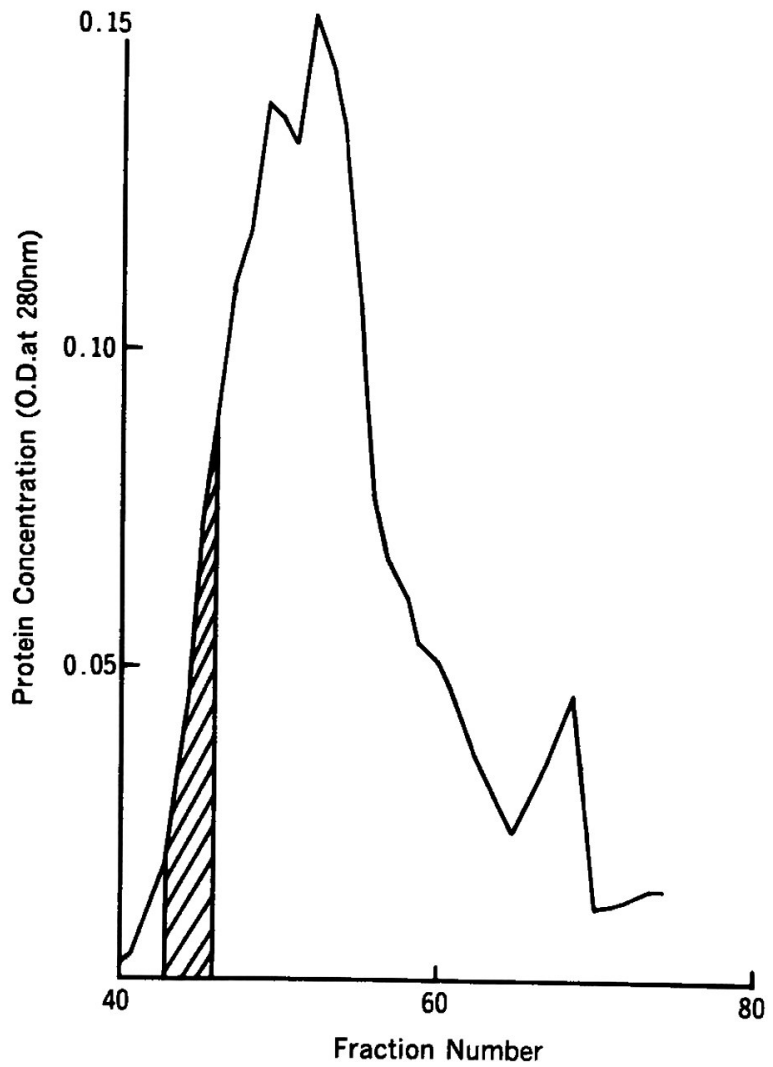

Fic. 11. Extraction of the lysosomal proteins by DEAEcellulose column chromatography. The 15-24 fractions from the Sephadex G-100 column were used. TMPase activity was detected in the $43-46$ fractions. sulfate. Strong TMPase activity was detected in the $60-80 \%$ fractions (Fig. 7). The protein was further desalted in a Sephadex G-100 column. TMPase was relatively early eluted and was found in the 15-24 fractions (Figs. 8, 9). The molecular weight of TMPase

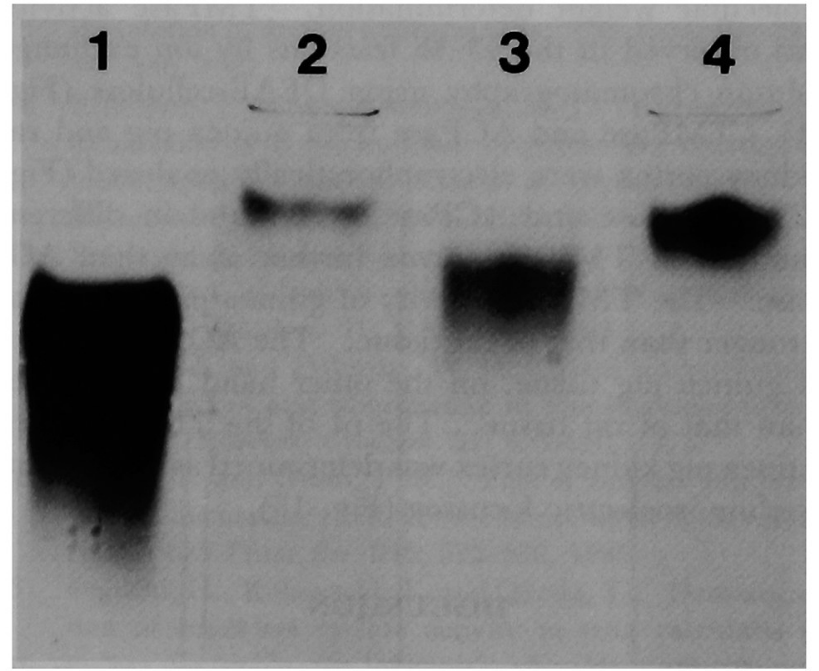

Fig. 12. Electrophoresis of TMPase and ACPase. Fractions of $40-80 \%$ ammonium sulfate from the homogenate of kidney cortex of guinea pig and rat were used. Lane 1; TMPase from guinea pig, Lane 2; ACPase from guinea pig, Lane 3; TMPase from rat, Lane 4; ACPase from rat. TMPase was detected in a different band from ACPase.

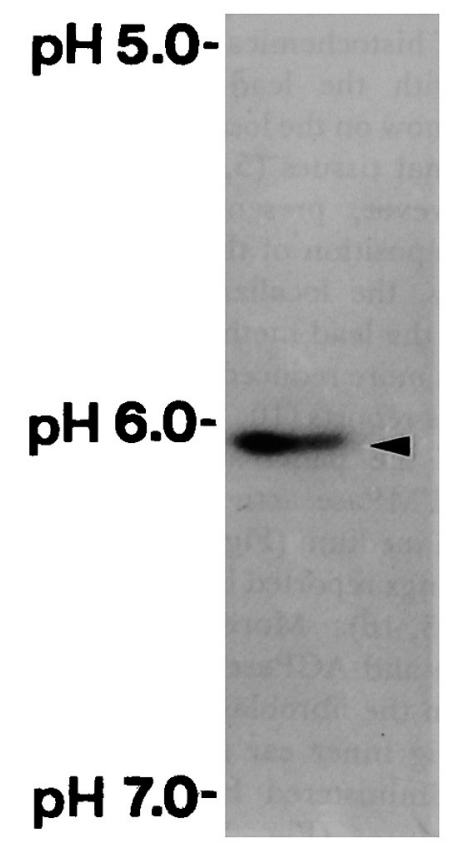

Fig. 13. Isoelectric focusing of TMPase from the lysosomal fraction of kidney cortex of guinea pig. Fractions collected from a Sephadex G-100 column were used. TMPase activity was detected as a single band situated at $\mathrm{pH} 6.1$. 
was determined as $130 \mathrm{KD}$ by Sephadex G-100 column chromatography (Fig. 10). Bovine serum globulin (150KD), phosphorylase A (94 KD), bovine serum albumin $(68 \mathrm{KD})$, ovalbumin $(43 \mathrm{KD})$ and trypsin $(23.3 \mathrm{KD})$ were employed as markers for the molecular weight determination. TMPase activity was observed in the 43-46 fractions by ion exchange column chromatography using DEAE-cellulose (Fig. 11). TMPase and ACPase from guinea pig and rat kidney cortex were electrophoretically analyzed (Fig. 12). TMPase and ACPase were found in different bands, and TMPase moved further away than ACPase. The TMPase activity of guinea pig tissue was stronger than that of rat tissue. The ACPase activity of guinea pig tissue, on the other hand, was weaker than that of rat tissue. The $\mathrm{pI}$ of the TMPase from guinea pig kidney cortex was determined as 6.1 by Ampholine isoelectric focusing (Fig. 13).

\section{DISCUSSION}

TMPase catalyzes the conversion of cyclic trimetaphosphate to tripolyphosphate in the acidic range (16). This enzyme is broadly classified as an acid phosphatase, and together with ACPase, is now considered as a reliable marker enzyme for the lysosomal system, which in the past could be only identified by nonspecific acid phosphatase, using $\beta$-glycerophosphate or cytidine $5^{\prime}$-monophosphate as substrate. A large body of histochemical and cytochemical studies performed with the lead-based method has been published by now on the localization of the TMPase activity in animal tissues $(5,6,12,14-18,22)$. This method, however, presents such disadvantages as nonspecific deposition of the reaction product. In the present study, the localization of TMPase was the same as with the lead method, and background staining was much more reduced than with lead, which confirms previous reports $(10,19,20)$. The basal tubular lysosomes of the pancreatic acinar cells were also positive for TMPase activity when incubated in the cerium-based medium (Fig. 6), which is in agreement with the findings reported by Oliver with the lead-based method $(15,16)$. Moreover, judging from the fact that TMPase and ACPase activities showed different localization in the fibroblasts of the spiral ligament of the guinea pig inner ear (Figs. 3, 4), and since exogenously administered HRP was observed in the tubular structures (Fig. 5), it was concluded that TMPase and ACPase are localized in two different types of structures, and that they are closely related to pinocytosis. The cerium-based method was, therefore, considered reliable for the histochemical detection of TMPase activity.

The TMPase reaction involves the reduction of tripolyphosphate, the reaction product of the enzyme activity, into orthophosphate by tripolyphosphatase and pyrophosphatase $(2,3)$; a complicated reaction which has made difficult its biochemical characterization and, therefore, its purification. In order to assay TMPase activity, we developed a simple method using the dot blot apparatus. TMPase was adsorbed onto nitrocellulose sheets, and its reaction product, tripolyphosphate, was insolubilized with lead salt on the nitrocellulose sheets. The enzyme activity was visualized with ammonium sulfide. This method permits the direct detection of TMPase activity in tissue and provides an easier and more rapid means for its measurement. We succeeded in the biochemical characterization of the partially purified TMPase and demonstrated that TMPase and ACPase are two different enzymes. Further immunohistochemical studies with anti-TMPase antibodies are, however, necessary in order to clarify the function of the TMPase-positive structures.

\section{REFERENCES}

1. Beaudoin, A. R., Grondin, G., Lord, A. and Pelletier, M.: $\beta$-NADPHase- and TMPase-positive "snake-like tubules" in the exocrine pancreas. Cytochemical and immunocytochemical studies. J. Histochem. Cytochem. 33; 569-575, 1985.

2. Berg, G. G. and Gordon, L. H.: Presence of trimetaphosphatase in the intestinal mucosa and properties of the enzyme. J. Histochem. Cytochem. 8; 85-91, 1960.

3. Berg, G. G.: The staining of trimetaphosphatases by the chelate removal method. J. Histochem. Cytochem. 12; 341$358,1964$.

4. Chu, N. M., Janckila, A. J., Wallace, J. H. and Yam, L. T.: Assessment of a method for immunochemical detection of antigen on nitrocellulose membranes. $J$. Histochem. Cytochem. 37; 257-263, 1989.

5. Doty, S. B., Smith, C. E., Hand, A. R. and Oliver, C.: Inorganic trimetaphosphatase as a histochemical marker for lysosomes in light and electron microscopy. J. Histochem. Cytochem. 25; 1381-1384, 1977.

6. Ellinger, A. and Pavelka, M.: Colchicine-induced tubular, vesicular and cisternal organelle aggregates in absorptive cells of the small intestine of the rat. I. Morphology and phosphatase cytochemistry. Biol. Cell 52; 43$52,1984$.

7. Graham, R. C. and Karnovsky, H. J.: The early stages of absorption of injected horseradish peroxidase in the proximal tubules of mouse kidney: Ultrastructural cytochemistry by a new technique. $J$. Histochem. Cytochem. 14; 291-302, 1966. 
8. Gomori, G.: Microscopic histochemistry: Principles and Practice. University of Chicago Press, Chicago, 1952.

9. Huet, J., Sentenac, A. and Fromageot, P.: Spot-immunodetection of conserved determinants in eukaryotic RNA polymerase. J. Biol. Chem. 257; 2613-2618, 1982.

10. Kobayashi, T., Okada, T. and Seguchi, H.: Cerium-based cytochemical method for detection of ouabain-sensitive, potassium-dependent p-nitrophenylphosphatase activity at physiological $\mathrm{pH}$. J. Histochem. Cytochem. 35; 601-611, 1987.

11. Kornberg, A.: Tripolyphosphate of trimetaphosphate in yeast extracts. J. Biol. Chem. 218; 23-31, 1956.

12. Livne, E. and Oliver, C.: Internalization of cationized ferritin by isolated pancreatic acinar cells. J. Histochem. Cytochem. 34; 167-176, 1986.

13. Okada, T., Seguchi, H. and Ogawa, K.: Acid phosphatase activities in the transitional epithelium of canine urinary bladder. Acta Histochem. Cytochem. 15; 639-647, 1982.

14. Oliver, C.: Cytochemical localization of acid phosphatase and trimetaphosphatase activities in exocrine acinar cells. J. Histochem. Cytochem. 28; 78-81, 1980.

15. Oliver, C.: Endocytic pathways at the lateral and basal cell surfaces of exocrine acinar cells. J. Cell Biol. 95; 154$161,1982$.

16. Oliver, C.: Characterization of basal lysosomes in exocrine acinar cells. J. Histochem. Cytochem. 31; 12091216, 1983.
17. Petty, H. R., Hermann, W. and McConnell, H. M. Cytochemical study of macrophage lysosomal inorganic trimetaphosphatase and acid phosphatase. $J$. Ultrastruct. Res. 90; 80-88, 1985.

18. Payer, A. F., Battle, C. L. and Peake, P. L.: Ultrastructural and cytochemical effects of trypan blue on TSH stimulation of thyroid follicular cells. Cell Tissue Res. 218; 547-556, 1981.

19. Robinson, J. M. and Karnovsky, M. J.: Ultrastructural localization of $5^{\prime}$-nucleotidase in guinea pig neutrophils based upon the use of cerium as capture agent. $J$. Histochem. Cytochem. 31; 1190-1195, 1983.

20. Robinson, J. M. and Karnovsky, M. J.: Ultrastructural localization of several phosphatases with cerium. $J$. Histochem. Cytochem. 31; 1197-1208, 1983.

21. Sasaki, M. and Fishman, W. H.: Dual ultrastructural localization of acid phosphatase in mouse kidney tubule cell. J. Histochem. Cytochem. 21; 653-660, 1973.

22. Sasaki, T. and Grant, P. R.: Fate of annular gap junctions in the papillary cells of the enamel organ in the rat incisor. Cell Tissue Res. 246; 523-530, 1986.

23. Seguchi, H., Kobayashi, T. and Okada, T.: Demonstration of adenylate cyclase activity in stria vascularis of guinea pig cochlea (in Japanese). Equilibrium Res. Suppl. 4; 1-8, 1988.

24. Spurr, A. R.: A low-viscosity epoxy resin embedding medium for electron microscopy. J. Ultrastruct. Res. 26; 21-43, 1969. 